Instructions for authors, subscriptions and further details:

http://generos.hipatiapress.com

\title{
A Marathon Search for My Deserved Body: How a Chinese Male- to-Female Manages Gender Nonconformity
}

Fung Kei Cheng ${ }^{1}$

1) Hong kong

Date of publication: October 25th, 2020

Edition period: October 2020-February 2021

To cite this article: Cheng, F. K. (2020). A Marathon Search for My Deserved Body: How a Chinese Male-to-Female Manages Gender Nonconformity. Multidisciplinary Journal of Gender Studies, 9(3), 234-262. doi: $10.17583 /$ generos.2020.6206

To link this article: http://dx.doi.org/10.17583/generos.2020.6206

PLEASE SCROLL DOWN FOR ARTICLE

The terms and conditions of use are related to the Open Journal System and to Creative Commons Attribution License (CC-BY). 


\section{A Marathon Search for My Deserved Body: How a Chinese Male-to-Female Manages Gender Nonconformity}

Fung Kei Cheng

Hong kong

\section{Abstract}

The hegemony of dichotomous gender identity dominates the discourse on the issues of sex and gender. Through this means, irrational fear brings about prejudice, stigmatisation, discrimination, and exclusion towards individuals who suffer from gender nonconformity. Despite relevant substantial literature, there is a paucity of research on Chinese transgender people. This case study investigates how a Chinese trans-woman deals with her gender incongruence and anxiety through sex realignment surgery. It conducts in-depth, semi-structured interviews, and processes data by means of interpretative phenomenological analysis, with the help of a computerised qualitative data analysis package. It also carries out member checking to enrich triangulation effects. The results unmask the way the participant is being incrementally liberated from being a pretend man in her current state of half-mannon-woman, and her efforts in achieving the gender that she desires. This study reveals factors that influence the embodiment of bodily integrity and psychological adjustments against distress induced by gender nonconformity, therefore supporting the development of a gender-affirming society that benefits both individuals and public interests

Keywords: bodily integrity, gender dysphoria, stigma management, transphobia, transwoman 


\section{Una Búsqueda Maratoniana de Mi Cuerpo Sentido: Como un Hombre - hacia - una mujer China Maneja la Inconformidad de Género}

Fung Kei Cheng

Hong kong

\section{Resumen}

La hegemonía de la identidad de género dicotómica domina el discurso sobre las cuestiones de sexo y género. Por este medio, el miedo irracional genera prejuicios, estigmatización, discriminación y exclusión hacia las personas que padecen inconformidad de género. A pesar de la literatura sustancial relevante, hay una escasez de investigación sobre las personas transgénero chinas. Este estudio de caso investiga cómo una mujer trans china lidia con su incongruencia de género y su ansiedad a través de la cirugía de realineación sexual. Realiza entrevistas en profundidad, semiestructuradas y procesa datos mediante análisis fenomenológico interpretativo, con la ayuda de un paquete de análisis de datos cualitativos computarizado. También realiza comprobaciones de miembros para enriquecer los efectos de triangulación. Los resultados desenmascaran la forma en que el participante se libera progresivamente de ser un hombre fingido en su estado actual de mitad hombre y no mujer, y sus esfuerzos por lograr el género que desea. Este estudio revela factores que influyen en la encarnación de la integridad corporal y los ajustes psicológicos contra la angustia inducida por la no conformidad de género, apoyando así el desarrollo de una sociedad que afirma el género que beneficia tanto a las personas como a los intereses públicos.

Palabras clave: integridad corporal, disforia de género, manejo del estigma, transfobia, mujer trans 


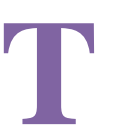

ransgender bewilderment has been documented in the literature throughout the years (Qi, 2002). In contrast, the hegemony of binary sex and gender dominates most cultures and societies (Ellis, McNeil, \& Bailey, 2014), emphasising distinct representations of masculinity and femininity. Such authoritarianism, together with the conventional assumptions of gender segregation and prejudice, induces comparatively widespread adverse reactions towards transgender people. This results in irrational fear, discrimination, marginalisation, stigmatisation (Kaplan et al., 2015), and injustice (Boyce, Barrington, Clare, Arandi, \& Paz-Bailey, 2012; Norton \& Herek, 2013), surprisingly even among medical professionals (Cicero \& Black, 2016). Although attention towards transgenderism has begun to increase since the 1960s, academic discussion remained inactive until the 1990s (Williams, 2014).

Transgender issues are connected to gender identity, and are an expression against a person's birth sex, which produces a conflict of "true gender self" (Ehrensaft, 2012, p. 341) and causes suffering from "selfpresentation bias" ( $\mathrm{Ku}$ et al., 2013, p. 6). This umbrella concept entails a variety of sexual variances such as full-time and part-time transgender individuals, transsexuals, transvestites, intersex people, and cross-dressers (Roberto, 2011), basically denoting discomfort over having the wrong body (Gazzola \& Morrison, 2014; Hines, 2007; Loeb, 2008; Rigney, 2003). Therefore, the sense of body hatred towards biological sex characteristics and functions (Raymond, 1994) enforces a longing upon transgender people to present an authentic self (Gagne \& Tewksbury, 1999) through their own means. This ambivalence towards gender identification, and their dissatisfaction regarding gender roles that deviate from social norms (Wen, 2009) yields biological, biopsychic, and intrapsychic distress (Ma, 1997); namely, gender dysphoria (Burdge, 2014) (a dissonance between body and mind among the transgendered).

In addition to gender dysphoria, an irrational hostility towards transsexual individuals (that is, transphobia) challenges transgender communities through harassment, discrimination and prejudices (Nadal, Davidoff, \& Fujii-Doe, 2014), and physical, sexual, and verbal violence (Bettcher, 2014), particularly in non-heterosexual-unfriendly environments in schools (Garvey \& Rankin, 2015; Hackimer \& Proctor, 2015) and 
workplaces (Priola, Lasio, De Simone, \& Serri, 2014). Such a phobia is mainly caused by misunderstandings and scant knowledge of sexuality (Siverskog, 2014). This disapproval not only fails to provide the transgendered with social safety, but even worse, increases social anxiety (Guzman-Parra et al., 2014), thereby bringing out secondary problems; for example, substance abuse (Nuttbrock, 2012), depression, and higher suicide risks (Boza \& Perry, 2014; Maguen \& Shipherd, 2010). These psychological problems result from internalised and structural stigma (Perez-Brumer, Hatzenbuehler, Oldenburg, \& Bockting, 2015). Apart from the abovementioned mental health detriments, a higher risk of HIV transmission among this underserved population (Jobson, Theron, Kaggwa, \& Kim, 2012) threatens public health.

Sex reassignment surgery plays a role in gender transformation, enabling transgender individuals to cope with gender ambiguity and gender incongruence (Drescher, Cohen-Kettenis, \& Winter, 2012; Lemma, 2013). It in turn changes one's gender to trans-women (male-to-female) or trans-men (female-to-male), and realises bodily integrity involving two domains. First, highlighting the ideas of wholeness and intactness (Slatman, 2012), bodily integrity supports the fulfilment of concordance between sex attributes and gender identity, thereby gaining the body with which the transgendered identify. Second, from a person-oriented perspective (Dekkers, 2009), it accentuates an "intrinsic right to control and autonomy over their bodies" (Mathur, 2008, p. 54), nourishing self-respect, self-definition, selfaffirmation, self-fulfilment, and volition-driven representation of self. This self identity (Ramachandran, 2009) retains physical and psychological inviolability (Slatman, 2012), and protects against bodily non-consensual interruption (Douglas, 2014) and an invasion against self-determination. In this sense, undergoing sex reassignment surgery is a bio-psycho-social decision (Shu \& Li, 2001) for preserving a dignified life via a process starting with the "self-destruction" (Finn \& Dell, 1999, p. 465) of an "alien body" (Youngson, 1999, p. 74) and culminating in the "self-production" (Finn \& Dell, 1999, p. 465) of a deserved body. Notwithstanding these merits, many transgender individuals only partly undergo sex reassignment surgery, or even undergo no surgical procedures at all, due to diverse concerns. They may instead utilise appearance enhancements and behaviours as a strategy of stigma management to veil their true selves; that is, passing 
(Goffman, 1963). They are perceived in their womanhood or manhood (Futty, 2010), possibly designating that they are socially recognised and accepted as the gender identity they expect. Therefore, they will be able to secure their rights to live as normal as they anticipate (Garfinkel, 1967).

Although a transgender population exists in most cultures, such as the hijara in India (Chakrapani, Shunmugam, Newman, Kershaw, \& Dubrow, 2015; Kalra, 2012), and kathoey (Winter, 2006) or sao braphet song (Costa \& Matzner, 2007) in Thailand, cultural and religious factors that are established against transsexuals (Bucar, 2010; Wood \& Conley, 2014) affect their mental wellness and quality of life (Yadegarfard, Ho, \& Bahramabadian, 2013). Transgender-related descriptions are not rare in Chinese classical literature (Liang, 2012; Liang \& Xu, 2012) and theatrical arts (Leung, 2012; Li, 2003; Wu, 2012a). Cross-gender acting was prevalent in ancient China (He, 2014; Kile, 2013), presenting gender fluidity (Zhou, 2012) in folk entertainment. Man-woman actors occupied major characters in Chinese operas, whereas women were required to be veiled at home and to keep their distance from male strangers. Interestingly, woman-man actresses have also contributed their talented performances to the modern Chinese film industry.

Research has estimated around 400,000 transgender people in China (Jiang, Wei, Zhu, Wang, \& Li, 2014). However, territory disparity indicates different attitudes due to historical backgrounds. Hong Kong Chinese infrequently demonstrate disgust towards the transgendered (King, Winter, \& Webster, 2009) since most of them are immersed into a westernised milieu that is relatively open. In mainland China, however, contradictions are observed. On the one hand, little explicit harm towards the transgendered results, but neglecting this unprivileged population is the normal practice (Jun, 2010). Indifference conceals this vulnerable group from public awareness and discussion, and so the public pays little attention to them. On the other hand, gradual legal normalisation (Zhang, 2015) favours their space, and attention is being paid to their sexual health (Best et al., 2015). Academia has focused on their legal rights following partial or full sex reassignment surgery (Wu, 2011, 2012b). Unsurprisingly, more complaints against man-to-woman than woman-to-man are detected because of cultural ideology (Ma, 1997, 1999): Chinese usually loathe men who act feminine, whereas in comparison they tend to accept masculine women. 
Despite the potential four hundred thousand transgender individuals involved, research investigating this community in China has been limited. This study explores personal experiences in carrying out the incremental process of sex reassignment surgery illustrated by a single case study of a Chinese male-to-female, who has been striving for bodily integrity to rectify the physical body she deserves. It also delves into the significance of perceived sex, which has determined her gender transition for passing. Outcomes not only extend the horizon of transsexual studies, but also shed light on social interactions with transgender people.

\section{Research Methods}

A single case study, also called a bounded case (Thomas, 2011), is adopted in this research to understand and describe a contemporary phenomenon through real-life situations and information-oriented narratives (Eisenhardt, 1989; Flyvbjerg, 2006). It is unique, experimental, and revelatory (Yin, 1989), largely supported by first-hand data (Hamel, Dufour, \& Fortin, 1993) and guided by a logical and systematic research design (Yin, 2009), including data collection, analysis, and trustworthiness.

The interview is a chief method for primary data collection in a case study (Rihoux \& Lobe, 2009). This project conducted in-depth, semistructured interviews through electronic mail and Skype communication. The researcher sent the interview questions to the participant, who responded concisely. This text interview was carried out twice prior to three Skype interviews totalling 329 minutes. The interviews were digitally recorded for transcribing afterwards. Also, multiple data sources were applied to enhance data richness (Yin, 2003), including the participant's blog and web pages from which deeper understandings of her social life were added. Such methodological pluralism marks not only data enrichment but also triangulation, used to optimise the dependability (reliability), credibility (validity), and confirmability (objectivity) of the qualitative research (Anney, 2014; Lietz \& Zayas, 2010; Shenton, 2004).

The unit of analysis was an individual; in this project, a purposiveselected informant. The researcher read the texts and transcriptions (from email and Skype interviews) repeatedly and utilised interpretative phenomenological analysis, with the assistance of a computerised qualitative 
data analysis package (ATLAS.ti 7), to explore the lived experience, and to engage in it with reflections from both the researcher and the researched, for a specific case of phenomenological psychology (Smith, Flowers, \& Larkin, 2009), deepening the understanding of the inner world of the participant. Three "super-ordinate themes" (Smith et al., 2009, p. 96) were organised; that is, gender identity, coming out, and bodily integrity. This paper focuses only on bodily integrity, which resulted from three "emergent themes" (Smith et al., 2009, p. 84); namely, liberating from being a pretend man, half-man-non-woman, and perceived sex.

This research is academically rigorous, and member-checking has been enforced. Aside from multiple data sources, as cited earlier, the participant proofread the verbatim transcriptions (of Skype interviews) in order to ensure their accuracy, which is crucial for data analysis. She also reviewed the early draft of this manuscript to avoid the researcher's data overinterpretation. Her efforts contributed to this project, yielding insight on transgender studies.

\section{Findings and Discussion}

This case study highlights how stressful it can be for a Chinese male-tofemale to be irritated by the gender ambiguity. Such stress presses her to pretend to be a man in order to conform to social norms even after she has partially undergone sex realignment surgery. In her present state of halfman-non-woman, she continues to alter minor sex cues to develop a successful presentation as a stronger perceived sex, which will be a determinant for the completion of her bodily modification. This case also analyses how she views her true self and embodies bodily integrity.

\section{Profile of the Participant}

Pippe (pseudonym), a middle-aged Chinese gender non-conformist in mainland China, is in charge of information technology at a university, and provides voluntary services for a web-based transgender magazine. As with many transgender individuals, her male body has distressed her since the onset of puberty (Tsoi, 1992; Vance, Ehrensaft, \& Rosenthal, 2014; Yadegarfard et al., 2013), since when she has loathed the development of sex characteristics such as a gravelly voice. This puzzled her, and her self- 


\section{Cheng - Chinese Gender Nonconformity}

seclusion has increased her loneliness (Yadegarfard et al., 2013) in adolescence.

In spite of being involuntarily tied to what she considered as a disgusting body, Pippe did not dare to express her feelings of depression over being a man, and remained closeted from her parents. However, she has fulfilled the traditional filial expectations of her parents (Chong \& Liu, 2016), through which she married a woman and has had a son to continue the family bloodline. She in fact was honest with her wife about her gender problem before marriage. Equivocally understanding her gender ambiguity, her wife innocently imagined an ordinary family life that has never come to pass in practice. The inevitable dissension arose in this conjugational relationship, due to which her wife let this secret out to her parents, who unwillingly accepted this fact. Although her son was too young to understand her gender confusion, Pippe briefly addressed the disparity from his friends' fathers, without giving him the details of her gender incongruence. Basically, she has relieved herself from this challenge within her immediate family members, which enables her to practically pursue her deserved body.

Her yearning to be a real woman grows continuously, and Pippe has pondered hopefully how to rectify her mistaken birth body (Alexander, 2005) with improvements in psychological well-being (de Vries et al., 2014). She has undergone partial sex reassignment surgery to depart gradually from being a pretend man, and is still searching to become a fully fledged woman who is able to realise her genuine self.

\section{Liberating from Being a Pretend Man}

Pippe reiterated her hatred of her own body having male sex characteristics, disowning her inherent sex. Nevertheless, being unable to deviate from social norms, she has been grudgingly pretending to be a man (such as through heterosexual marriage) to reduce the stress of being a minority (Ellis, Bailey, \& McNeil, 2015) with herself and with her family members, who inescapably have to cope with public pressure and bias. Having tired of such pretence, she has begun the marathon journey creating her deserved body.

Pippe's bodily perturbation came from her perception that a man's body is normally dirty, with smells and unfavourable secretions (Isaksen, 2002), 
which is completely different from the dainty woman's body that she admires. She elaborated on her abhorrence:

“[I'm] pretending as if I were a man. I'm sick of this pretence. ... I used to cry in a [close] friend's home. He knows my gender problem. Every time when I visited him, I cried unrestrainedly because that was the only place where I could release myself. I no longer had to pretend there. I cried freely and felt relaxed. ... I hate my own body. ... [I] can't accept my body. ... [I] feel [my] body is dirty. ... probably because of secretions, excessive secretions produce a strong smell. ... A man's body deposits smells, for example, sweat, and others. It's more greasy [than a female body]. I feel this isn't my body. It's very ugly, very dirty. This is [what I'm] feeling. For more than 10 years, I [have been] reluctant to look at myself in a mirror or take photos."

Being deprived of a woman's body, Pippe resented living in a foreign carrier, like a Hermit crab without a soul. She lost her body, her control, and her own self. She is carrying a husk with unappealing features, especially her voice, which is an identifier habitually signalling sex. This male voice is still her Achilles heel, which severely frustrates her, and because of which her birth sex is easily identified. In order to prevent hearing such unpleasing sounds from her throat, she was accustomed to keeping silence.

"[I] can't control the changes in my body [in puberty]; for instance, my voice. The voice is not that I want to hear. This shows up every time I have a phone call. ... He (her friend) gave me a 40-minute call in which I didn't say a sentence. I couldn't open my mouth. I really couldn't. I can't stand it (her voice). ... I don't want to use such a voice. ... It isn't soft, not fine, not feminine."

Presently Pippe is unable to change her voice but dressing enables her to alleviate her sex entanglement. When gender identity is a symbol (Xiong, 2014) for her, clothing is an expression of this symbol. She loves to dress in female clothing, wearing skirts with ornamentation and exhibiting a female figure. She is so contented that she will be taken to be a woman when she dresses in feminine clothing. She only does so when she is far away from home, unceasingly counterfeiting herself as a man to avoid embarrassment to her family. Nevertheless, in order to find a balance between her own 


\section{Cheng - Chinese Gender Nonconformity}

feelings and concerns for her family, she prefers to dress in a neutral style in daily life, a compromise in pretending to be a man. To her disappointment, this turns out to be a failure in passing herself off as the opposite sex, in that merely $10 \%$ of people may see her as a woman when she wears neutral fashions. She feels strongly disconcerted, and is hesitant in how much she can be read as a woman.

Such outcomes have opposed Pippe's expectations, leading to depression and suicidal ideation due to the imbalance between the efforts she has done and the return she expects. Such disappointment after her great effort to transform herself caused her to believe that death could potentially help her escape from this predicament. Her life is too harsh, meaningless, and full of contradictions without a proper body. She cried out tempted to give up:

“... such a meaningless life ... [I] was unable to build normal relationships with people. ... [I] was frustrated. [I] would rather die. ... I was depressed. I thought without the [desired] body, everything I did becomes meaningless. That is, everything is disconnected from me, and everything I've done is disconnected from me. I wanted to do nothing. ... I've put forth my greatest effort in order to persuade people to see me as a woman [but this has failed]. Such a failure strongly frustrates me. ... Why should I endure it (the failure)? ... [I] withdrew [and go] to the last step; that is, an escape. ... I've endured so many things but can get nothing. Sometimes I wanted to die. ... Sometimes when I crossed a road, I suddenly didn't want to continue and then stopped walking [in the middle of the road]. ... [I thought] this (death) was a solution."

Pippe is by no means yet resigned to continue to carry a man's body and conceal that fact she is a man, so she has made the serious decision towards body modification (Stone, 2013) in order to regain the freedom to access her authentic self (Sell, 2001). However, her bodily remedy has only reached halfway, and she despises the state of being neither man nor woman.

\section{Half-Man-Non-Woman}

Physical attractiveness is closely associated with self-image and social status for women (Adler, Kless, \& Adler, 1992). Pippe did not find about a 
path out of her gender non-conformity prior to body modification, and had considered how to commit suicide. She recalled her psychological struggle:

\begin{abstract}
“At that time, I really couldn't accept [my body]. I wanted to die. I also wanted to know people who want to die how to die. Suddenly, I thought I would suffer loss if I died because I hadn't done what I should do. Even if I needed to die, I should do something for myself. I had to change; therefore, I visited a doctor (a sex reassignment surgeon). I had them (testicles) removed [but no further operations yet], and [I] felt good. Death is not necessary then."
\end{abstract}

Since 2000, Pippe has begun hormonal treatment and takes estrogen, which beautifies her skin and hair (Winter \& Doussantousse, 2009), and produces breast growth, softening skin, and a reduction in muscle mass and strength (Wilczynski \& Emanuele, 2014). Although these do not thoroughly meet her requirements, she has received allowances towards gender expression (Riley, Clemson, Sitharthan, \& Diamond, 2013). She articulated her amazed responses to hormonal therapy:

“[My breast] has grown a bit. ... [The growth] isn't ideal but there is a bit [breast growth]. ... [Body] fats newly distribute. Thicker fats are on a female body than on a male. ... [My hair] is [now] softer, finer, and lighter in colour. [My] skin isn't as greasy as a male, more brisk and less acne. ... Male feet produced stronger smells. It (estrogen) inhibits smells. ... Once, I stopped taking estrogen [to prepare] for some surgery, I found [my] feet became stronger smelling [again]."

Despite the positive ramifications, Pippe has experienced some shortcomings:

"Because of estrogen insufficiency [perhaps as I'm taking a small amount], [I felt] a little bit menopausal [syndrome]. ... Sometimes [I] suddenly sweat. ... I'm still having such symptoms. I've asked doctors but they don't know how to deal with it. ... If I forget to take the drug (estrogen) for a few days, [my] acne will flare up."

Pippe reiterated her hatred of her own body. However, she is still maintaining her dilemma situation - half man and half woman - until she is 


\title{
245 Cheng - Chinese Gender Nonconformity
}

able to complete the entire alteration in the future, because she has not yet prepared for full sex reassignment at this moment. She perceives sex reassignment surgery differently from how she interprets sex distinctions, elucidating the following:

\begin{abstract}
"[Sex reassignment] surgery that makes you become a female can only convert [sex] organs. But nobody can see whether you (I) have the organs (female genitalia). Nobody will know whether I have the organs even if I've done the surgery. People won't feel what I've changed. Therefore, it doesn't matter whether I undergo the operation [to remove the penis and construct a vagina]. ... In fact, surgery can't make you [really] change from a man to a woman. It gives you a [sex] organ only. This is an [artificial sex] organ only. ... Nobody can see [my] reshaping [of anatomical sex] from the outward appearance. ... [Genital] surgery can't change the outward appearance [indicating genital difference]. It can change organs only. ... My current body is in the post-surgery state [which has shown augmented breasts, and finer skin and hair]."
\end{abstract}

Pippe repeatedly explained that sex reassignment surgery is unable to change one's sex thoroughly but solely enables the transgendered to keep close to the sex with which they identify. For instance, the surgery cannot alter genes and the skeleton. Nor does it allow trans-women to be able to procreate, or facilitate sexual pleasure. For these constraints, she enumerated a set of loose criteria for her completion of the surgery: self conditions, environment, financial capacity, and psychological needs. She was unable to explain these terms clearly; however, she summarised the key consideration using the word image. The image she emphasised refers to being perceived or read as a woman, at least superficially.

"If most people see me not as a man, I'll change [the genitalia]. ... Therefore, I'll do some more improvements first, which direct people to think I'm a woman. When most of them see me as a woman, I'll go to dig a hole (vaginal construction). ... At that time, I'll take the last step (vaginal construction). ... [What I mean] is not people I know but people I don't know, that is, strangers. ... How can I know whether people see me as a woman? Through contact, I can observe how people see me. I will then assess further. If most strangers feel that I'm a 
woman, I think I (my feminine image) am alright. But if they see me as a man, I think it (genitalia construction) won't be necessary. ... In a nutshell, the image is the primary issue. ... For example, a woman usually has apparent breasts. But you still feel a [genetic] woman with plain breasts is a woman. But you won't feel that a man who has done [genital] surgery with plain breasts is a woman."

Her present state of half-man-non-woman has afflicted Pippe, which hinders her from passing as a woman and has degraded her quality of life. This dissatisfaction motivates her to continue the transition in managing her body in such a way that people will perceive her as a woman:

"I've done small operations (cosmetic surgery) to remove visible male characteristics. I had heavy beard, and I did away with it. This is terrible. ... Currently, laser technology is used to burn it (beard) out. It (laser) doesn't create too many cuts. It burns directly on my face more than a hundred strikes every visit. I've paid for 11 visits. ... It (the laser operation) covers [an area] as small as a piece of a finger nail at every visit. ... The hair follicles were burnt out. After 11 visits, there're still pertinacious ones. I pluck them manually. As strong laser was applied due to such a heavy beard, it sometimes burned my face. But I didn't use anaesthetic. ... It was pretty painful, and felt like being hit by a rubber band [when applying every strike]; perhaps more painful than acupuncture, totalling more than a thousand strikes. In fact, I was aching but I could bear it. ... I've done different operations. The pain is inevitable but I'm happy. ... Physical pain is nothing, but psychological pain hurts [me much].”

In addition, searching for a reliable physician to undertake liposuction, Pippe wants to gain a slimmer waist in order to be more feminine. She has also started vocal training to acquire a voice closer to her requirements even though the effects are far behind her anticipation. These actions reflect how Pippe perceives femininity and differentiates between physiological sex and perceived sex, that is in her case, between a physiological woman and a perceived woman. 


\section{Cheng - Chinese Gender Nonconformity}

\section{Perceived Sex}

Transgender individuals suffer from a gender identity in opposition to their inherent sex, which triggers their awareness of gender autonomy as a fundamental right (Weiss, 2010) to realise bodily integrity. However, their experiences in such self-determination vary from person to person as long as sex reassignment surgery is a major possibility for full or partial modification. Pippe recalled her feelings when she received an electronic note from her friend:

"A few days ago, I received a mobile message from a friend who has just finished her [full set of sex reassignment] surgery in Thailand. She was very happy. I admire her very much, and I'm upset for myself, my situation."

Although Pippe is very eager to become a full woman, she has carried out only those parts of the surgery which cause her feminine cues to become visible, as per her expectations; for instance, through finer skin. This suspension of further bodily alteration causes her struggles against her primary intentions to linger, because that depends on how she values her sexual presentation, which is strongly linked to the perceptions of other people around her. She has been making great effort to enhance her gender visibility and convince people that she is a woman through discernible attributes such as hair and appearance. Such perceived sex will indicate how much she has been socially identified (Patosalmi, 2009) as a woman, that is, passing (Bischoff, 2011), from which she can achieve greater satisfaction. In this case, genitalia construction is outside of her immediate goals since it does not give an obvious identifiable sign that can differentiate her sex before and after surgery, implying that her physiological sex is unable to solve her discontent with gender identity.

Passing is a prominent concept for both internal and external purposes (Bischoff, 2011). Pippe will feel satisfied if she can achieve visual conformity. In fact, her urge to pass as a woman is a need within her social life that is necessary to reduce embarrassment, exemplified in a recent encounter as she had: 
"When I joined a trip with my friends who even knew my gender ambiguity, I was annoyed over the hesitation on with whom I shared a room. If my roommate was a man, I felt uneasy. But if I shared a room with a woman, she might feel uneasy. ... If they had seen me as a woman, men wouldn't share a room with me but women would do so willingly. ... They'd respect me as a woman. They'd take consideration of me as how a woman feels. ... This (perceived sex and/or passing) is a practical issue. If others see me as a woman, they'll treat me as a woman and I can minimise unnecessary mess."

Importantly, Pippe accepts the discrepancy that exists in that passing is only passing and that perceived sex is not identical to birth sex (Koch-Rein, 2006), regardless of how much others read transgendered individuals as their desired gender. She explained:

"I understand that I'll never be an [inherent] woman even though I've proceeded with genital construction. You can tell whether one is a man or a woman from many aspects, including behaviour, vocabulary, and mannerism. No matter how close you can perform, some people can know your original sex from your transformed sex through gut feelings. I'm too rational not to accept this reality. But I still want a woman's body, and I want people to see me as a woman."

Gender identity for Pippe is connected not only to her "transgender self" (Fraser, 2009, p. 126) but more crucially to the societal self (Wolfradt \& Neumann, 2001) (the association between an individual and society). Passing as one's perceived sex represents the social domain of the transgendered, revealing the fact that human beings are both isolated beings and social beings (Fromm, 1971). Realising the "social self" (Mead, 1913, p. 374) from the subject $I$ and the object $m e$ reflects the significance of intersubjectivity (Slatman \& Widdershoven, 2010) through person-to-person dynamics (Stanghellini \& Lysaker, 2007). Transgender people seek both $I$ and $m e$ as the gender they identify, which is also what matters to cisgender people. Pippe distinguishes physiological sex from perceived sex, in which the former may not necessarily coincide with the latter. However, this does not obstruct her from being passable as a woman. The destructive construction of sex reassignment surgery signifies a physio-psychosocial approach, where intrapersonal emotions are tightly interweaved with 
interpersonal interaction. This intra-interpersonal dynamics illuminates that in addition to being a private, personalised possession, the body involves social recognition (Gracia, 1998).

\section{Implications}

Gender dysphoria exposes gender non-conformity as the transgendered suffer. In accordance with the fifth edition of the Diagnostic and Statistical Manual of Mental Disorders (DSM-5) (American Psychiatric Association, 2013), it has been de-pathologised. Rather than been as cases, the transgendered should be respected as subjects, as individuals, and their needs and life difficulties should be understood (Ma, 1999).

There is a range of acts that can magnify bodily autonomy and accommodate the preferred gender tendency of the transgendered, such as cross-dressing, and plastic and cosmetic surgery, which is subservient to attaining better perceived sex and ability to pass as the desired sex. Additionally, body ownership combines the senses of corporeality and psychological satisfaction (Schotsmans, 1998). Although gender nonconformity has been redefined as not being a mental illness, the rate of mental problems in this vulnerable community is higher than that in the general population (Hoffman, 2014; Nuttbrock et al., 2010). This group faces challenges not only of internal conflicts concerning their "authentic gender self" (Ehrensaft, 2014, p. 574) but also of social exclusion (Kerry, 2014). Failure to pass as their desired sex frustrates their social life and mental wellness. Therefore, helping them present themselves in the desired way is of foremost importance, and is a collective effort on the part of the transgendered, social policy decision makers, medical service practitioners, legal professionals, and scholars.

Indispensably, governmental resources play a leadership role in spearheading advocacy for transgender equality. Affirmative campaigns for this disadvantaged population are viable through public education and the legal establishment to protect their rights in the public space, school, the workplace, family and marriage, and health equity (Lo \& Horton, 2016; Reisner et al., 2016; Winter et al., 2016). Hence, in order to educate the public in the awareness of gender dysphoria, it is suggested that educational curricula be reformed in order to introduce gender variance (Bilodeau \& 
Renn, 2005) to youngsters, which can reduce peer-to-peer bullying in school. Also, psychoeducation should be provided to both families with transgender children (Harper \& Singh, 2014) and other parents so as to increase the acceptance of transgenderism.

There is a limited supply of transgender-specific mental health providers and psychological consultants, even though emotional problems are not rare among the transgendered. Updated knowledge of gender identity and polished communication skills (Hagen \& Galupo, 2014) are recommended for improving the competencies and professionalism of therapists, especially for the pre-operation and post-operation stages of transgender clients. A comprehensive competent care includes empathy and sensitivity to gender concerns, such as body image, sexual issues, social rapport, and religious factors, to develop a more robust resilience among transsexual persons.

A spectrum of community, professional and peer support for the transgendered and their families (Graham et al., 2014; Kuvalanka, Weiner, \& Mahan, 2014) is critical for creating a trans-affirming society (Singh, Meng, \& Hansen, 2013). A trans-friendly environment benefits gender diversity and inclusiveness, together with a reduction in social costs, for example, in mental health expenditures, and suicide prevention.

Of significance, it is proposed that transgendered individuals review how they engage self-determination in ways that rely on how they interpret bodily integrity. Excessive dependence on the effects of passing implies the surrender of their autonomy. Their rich experience in sensing both femininity and masculinity indeed enables them to understand the sexes more deeply. This uniqueness paints their life in a more colourful way, dissipating gender-precipitated tribulations.

\section{Limitations}

This single case specifies the personal experiences of the participant, which does not tend to result in generalisation in the transgender population since the primary objective of a case study is to explore an assigned lived experience. A larger sample size is suggested for forthcoming projects. Also, it articulates a Chinese male-to-female, which may not reflect the life of 


\section{Cheng - Chinese Gender Nonconformity}

trans-men or transgender people in other cultures. Studies on these gaps may offer future research directions.

\section{Concluding Remarks}

Gender nonconformity is connected to personal, familial, and social dimensions, which produces interpersonal and intrapersonal isolation. The transgender individuals suffer from their wrong bodies when they confuse the gender identity and subsequently are afflicted by stress and self-hatred. Misunderstandings worsen fear in the public because the gender role of this group differs from the social norms. Simultaneously living in various worlds disorientates the transgendered: the social world, the inherent physical body, and the gender identification. Thus, the presentation of true self in these conflicts becomes an inevitable challenge for this marginalised group.

This case study argues that perceived sex, to a certain extent, is more important than physiological sex for some transgendered individuals for the sake of being better able to pass themselves off as their desired sex. In reflecting multiple layers of gender (biological sex, perceived sex, selfsatisfied gender, and social gender), it asserts the interactions between searching body and making body, from which bodily integrity creates meaning in gender identity, in passing, in social dynamics, and finally in life and existence. Apart from the fulfilment of intrapersonal identity, external gender recognition serves as an indicator of social acceptance that can minimise stigmatisation and inferiority. Hence, a gender variance friendly environment is conducive to creating a harmonious society.

\section{References}

Adler, P. A., Kless, S. J., \& Adler, P. (1992). Socialisation to gender roles: Popularity among elementary school boys and girls. Sociology of Education, 65(3), 169-187.

Alexander, J. (2005). Transgender rhetorics: (Re)composing narratives of the gendered body. College Composition and Communication, 57(1), 45-82.

American Psychiatric Association. (2013). Diagnostic and statistical manual of mental disorders: DSM-5. Washington, DC: American Psychiatric 
Association.

Anney, V. N. (2014). Ensuring the quality of the findings of qualitative research: Looking at trustworthiness criteria. Journal of Emerging Trends in Educational Research and Policy Studies, 5(2), 272-281.

Best, J., Tang, W., Zhang, Y., Han, L., Liu, F., Huang, S., Yang, B., Wei, C., \& Tucker, J. D. (2015). Sexual behaviours and HIV/syphilis testing among transgender individuals in China: Implications for expanding HIV testing services. Sexually Transmitted Diseases, 42(5), 281285. doi: 10.1097/OLQ.0000000000000269

Bettcher, T. M. (2014). Transphobia. Transgender Studies Quarterly, 1(1-2), 249-251. doi: 10.1215/23289252-2400181

Bilodeau, B. L., \& Renn, K. A. (2005). Analysis of LGBT identity: Development models and implications for practice. New Directions for Student Services, 111, 25-39.

Bischoff, A. (2011). Passing the test: The transgender self, society and femininity. Retrieved May 30, 2016, from http://digitalcollections.sit.edu/isp_collection/1155.

Boyce, S., Barrington, B., Clare, H., Arandi, C. G., \& Paz-Bailey, G. (2012). Facilitating access to sexual health services for men who have sex with men and male-to-female transgender persons in Guatemala City. Culture, Health and Sexuality, 14(3), 313-327. doi: 10.1080/13691058.2011.639393

Boza, C., \& Perry, K. N. (2014). Gender-related victimisation, perceived social support, and predictors of depression among transgender Australians. International Journal of Transgenderism, 15(1), 35-52. doi: $10.1080 / 15532739.2014 .890558$

Bucar, E. M. (2010). Bodies at the margins: The case of transsexuality in Catholic and Shia ethics. Journal of Religious Ethics, 38(4), 601615.

Burdge, B. J. (2014). Being true, whole, and strong: A phenomenology of transgenderism as a valued life experience. Journal of Gay and Lesbian Social Services, 26(3), 355-382. doi: 10.1080/10538720.2014.926232

Chakrapani, V., Shunmugam, M., Newman, P. A., Kershaw, T., \& Dubrow, R. (2015). HIV status disclosure and condom use among HIVpositive men who have sex with men and Hijras (male-to-female 


\section{Cheng - Chinese Gender Nonconformity}

transgender people) in India: Implications for prevention. Journal of HIV/AIDS and Social Services, 14(1), 26-44. doi: $10.1080 / 15381501.2013 .859113$

Chong, A. M. L., \& Liu, S. (2016). Receive or give? Contemporary views among middle-aged and older Chinese adults on filial piety and well-being in Hong Kong. Asia Pacific Journal of Social Work and Development. doi: 10.1080/02185385.2015.1131619

Cicero, E. C., \& Black, B. P. (2016). I was a spectacle ... A freak show at the circus: A transgendered person's ED experience and implications for nursing practice. Journal of Emergency Nursing, 42(1), 25-30. doi: 10.1016/j.jen.2015.08.012

Costa, L. M., \& Matzner, A. J. (2007). Male bodies, women's souls: Personal narratives of Thailand's transgendered youth. New York: The Haworth Press, Inc.

de Vries, A. L. C., McGuire, J. K., Steensma, T. D., Wagenaar, E. C. F., Doreleijers, T. A. H., \& Cohen-Kettenis, P. T. (2014). Young adult psychological outcome after puberty suppression and gender reassignment. Pediatrics, 134(4), 696-704. doi: 10.1542/peds.20132958

Dekkers, W. (2009). Routine (non-religious) neonatal circumcision and bodily integrity: A transatlantic dialogue. Kennedy Institute of Ethics Journal, 19(2), 125-146.

Douglas, T. (2014). Criminal rehabilitation through medical intervention: Moral liability and the right to bodily integrity. Journal of Ethics, 18, 101-122. doi: 10.1007/s10892-014-9161-6

Drescher, J., Cohen-Kettenis, P., \& Winter, S. (2012). Minding the body: Situating gender identity diagnoses in the ICD-11. International Review of Psychiatry, 24(6), 568-577. doi: 10.3109/09540261.2012.741575

Ehrensaft, D. (2012). From gender identity disorder to gender identity creativity: True gender self child therapy. Journal of Homosexuality, 59(3), 337-356. doi: 10.1080/00918369.2012.653303

Ehrensaft, D. (2014). Found in transition: Our littlest transgender people. Contemporary Psychoanalysis, 50(4), 571-592. doi: 10.1080/00107530.2014.942591

Eisenhardt, K. M. (1989). Building theories from case study research. 
Academy of Management Review, 14(4), 532-550.

Ellis, S. J., Bailey, L., \& McNeil, J. (2015). Trans people's experiences of mental health and gender identity services: A UK study. Journal of Gay and Lesbian Mental Health, 19(1), 4-20. doi: 10.1080/19359705.2014.960990

Ellis, S. J., McNeil, J., \& Bailey, L. (2014). Gender, stage of transition and situational avoidance: A UK study of trans people's experiences. Sexual and Relationship Therapy, 29(3), 351-364. doi: 10.1080/14681994.2014.902925

Finn, M., \& Dell, P. (1999). Practices of body management: Transgenderism and embodiment. Journal of Community and Applied Social Psychology, 9, 463-476.

Flyvbjerg, B. (2006). Five misunderstandings about case-study research. Qualitative Inquiry, 12(2), 219-245.

Fraser, L. (2009). Depth psychotherapy with transgender people. Sexual and $\begin{array}{llll}\text { Relationship Therapy, } & \text { 24(2), } & \text { 126-142. doi: } \\ \text { 10.1080/14681990903003878 } & & \end{array}$

Fromm, E. (1971). The crisis of psychoanalysis: Essays on Freud, Marx, and social psychology. Greenwich, USA: Fawcett Publications, Inc.

Futty, J. T. (2010). Challenges posed by transgender: Passing within ambiguities and interrelations. Graudate Journal of Social Science, 7(2), 57-75.

Gagne, P., \& Tewksbury, R. (1999). Knowledge and power, body and self: An analysis of knowledge systems and the transgendered self. The Sociological Quarterly, 40(1), 59-83.

Garfinkel, H. (1967). Studies in ethnomethodology. Englewood Cliffs, USA: Prentice-Hall.

Garvey, J. C., \& Rankin, S. R. (2015). The influence of campus experiences on the level of outness among trans-spectrum and queer-spectrum students. Journal of Homosexuality, 62(3), 374-393. doi: 10.1080/00918369.2014.977113

Gazzola, S. B., \& Morrison, M. A. (2014). Cultural and personally endorsed stereotypes of transgender men and transgender women: Notable correspondence or disjunction. International Journal of Transgenderism, 15(2), 76-99. doi: 10.1080/15532739.2014.937041 Goffman, E. (1963). Stigma: Notes on the management of spoiled identity. 
London, UK: Penguin.

Gracia, D. (1998). Ownership of the human body: Some historical remarks.

In H. A. M. J. T. Have, J. V. M. Welie, \& S. F. Spicker (Eds.), Ownership of the human body: Philosophical considerations on the use of the human body and its parts in healthcare (pp. 67-79). Dordrecht, The Netherlands: Springer Science+Business Media B. $\mathrm{V}$.

Graham, L. F., Crissman, H. P., Tocco, J., Hughes, L. A., Snow, R. C., \& Padilla, M. B. (2014). Interpersonal relationships and social support in transitioning narratives of Black transgender women in Detroit. International Journal of Transgenderism, 15(2), 100-113. doi: 10.1080/15532739.2014.937042

Guzman-Parra, J., Paulino-Matos, P., de Diego-Otero, Y., Perez-Costillas, L., Villena-Jimena, A., Garcia-Encinas, M. A., \& Bergero-Miguel, T. (2014). Substance use and social anxiety in transsexual individuals. Journal of Dual Diagnosis, 10(3), 162-167. doi: 10.1080/15504263.2014.930658

Hackimer, L., \& Proctor, S. L. (2015). Considering the community influence for lesbian, gay, bisexual, and transgender youth. Journal of Youth Studies, 18(3), 277-290. doi: 10.1080/13676261.2014.944114

Hagen, D. B., \& Galupo, M. P. (2014). Trans individuals' experiences of gendered language with health care providers: Recommendations for practitioners. International Journal of Transgenderism, 15(1), 16-34. doi: 10.1080/15532739.2014.890560

Hamel, J., Dufour, S., \& Fortin, D. (1993). Case study methods. California: Sage Publications, Inc.

Harper, A., \& Singh, A. (2014). Supporting ally development with families of trans and gender nonconforming (TGNC) youth. Journal of LGBT Issues in Counselling, 8(4), 376-388. doi: 10.1080/15538605.2014.960127

He, C. (2014). Performance and the politics of gender: Transgender performance in contemporary Chinese films. Gender, Place and Culture: A Journal of Feminist Geography, 21(5), 622-636. doi: 10.1080/0966369X.2013.810595

Hines, S. (2007). (Trans)forming gender: Social change and transgender citizenship. Sociological Research Online, 12(1), 1-14. doi: 


\section{$10.5153 /$ sro. 1469}

Hoffman, B. R. (2014). The interaction of drug use, sex work, and HIV among transgender women. Substance Use and Misuse, 49(8), 10491053. doi: 10.3109/10826084.2013.855787

Isaksen, L. W. (2002). Masculine dignity and the dirty body. NORA - Nordic Journal of Feminist and Gender Research, 10(3), 137-146. doi: $10.1080 / 080387402321012162$

Jiang, H., Wei, X., Zhu, X., Wang, H., \& Li, Q. (2014). Transgender patients need better protection in China. The Lancet, 384, 2108-2109.

Jobson, G. A., Theron, L. B., Kaggwa, J. K., \& Kim, H.-J. (2012). Transgender in Africa: Invisible, inaccessible, or ignored. Journal of Social Aspects of HIV/AIDS, 9(3), 160-163. doi: 10.1080/17290376.2012.743829

Jun, P. (2010). Transgender in China. Journal of LGBT Youth, 7(4), 346-358. doi: 10.1080/19361653.2010.512518

Kalra, G. (2012). Hijras: The unique transgender culture of India. International Journal of Culture and Mental Health, 5(2), 121-126. doi: 10.1080/17542863.2011.570915

Kaplan, R. L., Wagner, G. J., Nehme, S., Aunon, F., Khouri, D., \& Mokhbat, J. (2015). Forms of safety and their impact on health: An exploration of HIV/AIDS-related risk and resilience among trans women in Lebanon. Health Care for Women International, 36(8), 917-935. doi: 10.1080/07399332.2014.896012

Kerry, S. C. (2014). Sistergirls/brotherboys: The status of indigenous transgender Australians. International Journal of Transgenderism, 15(3-4), 173-186. doi: 10.1080/15532739.2014.995262

Kile, S. E. (2013). Transgender performance in early modern China. differences: A Journal of Feminist Cultural Studies, 24(2), 130-149. doi: 10.1215/10407391-2335085

King, M. E., Winter, S., \& Webster, B. (2009). Contact reduces transprejudice: A study on attitudes towards transgenderism and transgender civil rights in Hong Kong. International Journal of Sexual Health, 21(1), 17-34. doi: 10.1080/19317610802434609

Koch-Rein, A. (2006). Passing moments: FTM-bodies in contemporary transgender photography. ZtG Bulletin Texte, 32, 156-179.

Ku, H.-L., Lin, C.-S., Chao, H.-T., Tu, P.-C., Li, C.-T., Cheng, C.-M., Su, T.- 
P., Lee, Y.-C., \& Hsieh, J.-C. (2013). Brain signature characterising the body-brain-mind axis of transsexuals. PloS One, 8(7, e70808), 18. doi: 10.1371/journal.pone. 0070808

Kuvalanka, K. A., Weiner, J. L., \& Mahan, D. (2014). Child, family, and community transformations: Findings from interviews with mothers of transgender girls. Journal of GLBT Family Studies, 10(4), 354379. doi: 10.1080/1550428X.2013.834529

Lemma, A. (2013). The body one has and the body one is: Understanding the transsexual's need to be seen. The International Journal of Psychoanalysis, $\quad 94, \quad 277-292 . \quad$ doi: $10.1111 / \mathrm{j} .1745-$ 8315.2012.00663.x

Leung, H. H.-S. (2012). Trans on screen. In H. Chiang (Ed.), Transgender China (pp. 183-198). New York: Palgrave Macmillan.

Li, S. L. (2003). Cross-dressing in Chinese opera. Hong Kong: Hong Kong University Press.

Liang, M.-y. 梁. (2012). On the transsexual phenomena and the relevant culture in ancient Chinese Literature 論中國古代文學中的變性人 現象與文化. Journal of Neijiang Normal University (Social Sciences) 內江㸝範學院學報（社會科學），27(3), 37-41.

Liang, M. Y. 梁., \& Xu, Z. L. 徐. (2012). On the transsexual phenomena and the relevant culture in dynasties of Ming and Ching 淺探明清文學 中的變性人現象與文化的關係. Times Literature 時代文學，2， 183-184.

Lietz, C. A., \& Zayas, L. E. (2010). Evaluating qualitative research for social work practitioners. Advances in Social Work, 11(2), 188-202.

Lo, S., \& Horton, R. (2016). Transgender health: An opportunity for global health equity. The Lancet, 2016(June 17), 1-3. doi: 10.1016/S01406736(16)30675-4

Loeb, E. (2008). Cutting it off: Bodily integrity, identity disorders, and the sovereign stakes of corporeal desire in US law. Women's Studies Quarterly, 36(3-4), 44-63.

Ma, J. L. C. (1997). A systems approach to the social difficulties of transsexuals in Hong Kong. Journal of Family Therapy, 19, 71-88.

Ma, J. L. C. (1999). Social work practice with transsexuals in Hong Kong who apply for sex reassignment surgery. Social Work in Health Care, 29(2), 85-103. doi: 0.1300/J010v29n02_05 
Maguen, S., \& Shipherd, J. C. (2010). Suicide risk among transgender individuals. Psychology and Sexuality, 1(1), 34-43. doi: $10.1080 / 19419891003634430$

Mathur, K. (2008). Body as space, body as site: Bodily integrity and women's empowerment in India. Economic and Political Weekly, 43(17), 54-63.

Mead, G. H. (1913). The social self. Journal of Philosophy, Psychology and Scientific Methods, 10, 374-380.

Nadal, K. L., Davidoff, K. C., \& Fujii-Doe, W. (2014). Transgender women and the sex work industry: Roots in systemic, institutional, and interpersonal discrimination. Journal of Trauma and Dissociation, 15(2), 169-183. doi: 10.1080/15299732.2014.867572

Norton, A. T., \& Herek, G. M. (2013). Heterosexuals' attitudes towards transgender people: Findings from a national probability sample of U.S. adults. Sex Roles, 68(11), 738-753. doi: 10.1007/s11199-0110110-6

Nuttbrock, L., Hwahng, S., Bockting, W., Rosenblum, A., Mason, M., Macri, M., \& Becker, J. (2010). Psychiatric impact of gender-related abuse across the life course of male-to-female transgender persons. The Journal of Sex Research, 47(1), 12-23. doi: $10.1080 / 00224490903062258$

Nuttbrock, L. A. (2012). Culturally competent substance abuse treatment with transgender persons. Journal of Addictive Diseases, 31(3), 236241. doi: 10.1080/10550887.2012.694600

Patosalmi, M. (2009). Bodily integrity and conceptions of subjectivity. Hypatia, 24(2), 125-141.

Perez-Brumer, A., Hatzenbuehler, M. L., Oldenburg, C. E., \& Bockting, W. (2015). Individual- and structural-level risk factors for suicide attempts among transgender adults. Behavioural Medicine, 41(3), 164-171. doi: $10.1080 / 08964289.2015 .1028322$

Priola, V., Lasio, D., De Simone, S., \& Serri, F. (2014). The sound of silence: Lesbian, gay, bisexual and transgender discrimination in inclusive organisations. British Journal of Management, 25, 488-502. doi: $10.1111 / 1467-8551.12043$

Qi, D. T. 祁. (2002). The soul betrays the body: Discussion on transsexualism 靈魂對肉體的背叛：變性人現象綜述. Chinese 
Journal of Sociology 社會, 4, 27-30.

Ramachandran, G. (2009). Against the right to bodily integrity: Of cyborgs and human rights. Denver University Law Review, 87(1), 1-57.

Raymond, J. G. (1994). The transsexual empire: The making of the shemale. New York: Teachers College Press.

Reisner, S. L., Poteat, T., Keatley, J., Cabral, M., Mothopeng, T., Dunham, E., Holland, C. E., Max, R., \& Baral, S. D. (2016). Global health burden and needs of transgender populations: A review. The Lancet, 2016(June 17), 1-23. doi: 10.1016/S0140-6736(16)00684-X

Rigney, M. (2003). Brandon goes to Hollywood: Boys don't cry and the transgender body in film. Film Criticism, 28(2), 4-71.

Rihoux, B., \& Lobe, B. (2009). The case for qualitative comparative analysis (QCA): Adding leverage for thick cross-case comparison. In D. Byrne \& C. C. Ragin (Eds.), The SAGA handbook of case-based methods (pp. 221-242). London, UK: SAGE Publications Limited.

Riley, E. A., Clemson, L., Sitharthan, G., \& Diamond, M. (2013). Surviving a gender-variant childhood: The views of transgender adults on the needs of gender-variant children and their parents. Journal of Sex and Marital Therapy, 39(3), 241-263. doi: 10.1080/0092623X.2011.628439

Roberto, K. R. (2011). Inflexible bodies: Metadata for transgender identities. Journal of Information Ethics, 20(2), 56-64. doi: 10.3172/JIE.20.2.56

Schotsmans, P. (1998). Ownership of the body: A personalist perspective. In H. A. M. J. Ten Have, J. V. M. Welie, \& S. F. Spicker (Eds.), Ownership of the human body: Philosophical considerations on the use of the human body and its parts in healthcare (pp. 159-172). Dordrecht, The Netherlands: Springer Science+Business Media B. $\mathrm{V}$.

Sell, I. (2001). Not man, not woman: Psychospiritual characteristics of a Western third gender. The Journal of Transpersonal Psychology, 33(1), 16-36.

Shenton, A. K. (2004). Strategies for ensuring trustworthiness in qualitative research projects. Education for Information, 22, 63-75.

Shu, L. 舒., \& Li, W. 李. (2001). Ethical thinking of transsexualism operation 變性術的倫理學思考. Chinese Medical Ethics 中國醫學 
倫理學, 79, 22-23.

Singh, A. A., Meng, S., \& Hansen, A. (2013). It's already hard enough being a student: Developing affirming college environments for trans youth. Journal of LGBT Youth, 10(3), 208-223. doi: $10.1080 / 19361653.2013 .800770$

Siverskog, A. (2014). They just don't have a clue: Transgender aging and implications for social work. Journal of Gerontological Social Work, 57(2-4), 386-406. doi: 10.1080/01634372.2014.895472

Slatman, J. (2012). Phenomenology of bodily integrity in disfiguring breast cancer. Hypatia, 27(2), 281-300.

Slatman, J., \& Widdershoven, G. (2010). Hand transplants and bodily integrity. Body and Society, 16(3), 69-92. doi: 10.1177/1357034X10373406

Smith, J. A., Flowers, P., \& Larkin, M. (2009). Interpretative phenomenological analysis: Theory, method and research. London, UK: SAGE Publications Limited.

Stanghellini, G., \& Lysaker, P. H. (2007). The psychotherapy of schizophrenia through the lens of phenomenology: Intersubjectivity and the search for the recovery of first- and second-person awareness. American Journal of Psychotherapy, 61(2), 163-179.

Stone, A. L. (2013). Flexible queers, serious bodies: Transgender inclusion in queer spaces. Journal of Homosexuality, 60(12), 1647-1665. doi: $10.1080 / 00918369.2013 .834209$

Thomas, G. (2011). How to do your case study: A guide for students and researchers. London: SAGE Publications Limited.

Tsoi, W. F. (1992). Male and female transsexuals: A comparison. Singapore Medical Journal, 33, 182-185.

Vance, S. R., Ehrensaft, D., \& Rosenthal, S. M. (2014). Psychological and medical care of gender nonconforming youth. Pediatrics, 134, 11841192. doi: $10.1542 /$ peds.2014-0772

Weiss, J. T. (2010). Gender autonomy, transgender identity and substantive due process: Finding a rational basis for Lawrence v. Texas. Journal of Race, Gender and Ethnicity, 5(1), 2-38.

Wen, Y. 文. (2009). The book of the gender traveller 性別漂泊的旅行者之 書. In J. C.-J. H. 何春芜萑 (Ed.), Queer sounding 酷兒新聲 (pp. 79119). Chungli, Taiwan 中壢, 台灣: National Central University 
Sex/Sexuality Research Centre 國立中央大學性/別研究室.

Wilczynski, C., \& Emanuele, M. A. (2014). Treating a transgender patient: Overview of the guidelines. Postgraduate Medicine, 126(7), 121128. doi: $10.3810 /$ pgm.2014.11.2840

Williams, C. (2014). Transgender. Transgender Studies Quarterly, 1(1-2), 232-234. doi: 10.1215/23289252-2400136

Winter, S. (2006). Thai transgenders in focus: Demographics, transitions and identities. International Journal of Transgenderism, 9(1), 15-27. doi: 10.1300/J485v09n01_03

Winter, S., \& Doussantousse, S. (2009). Transpeople, hormones, and health Risks in Southeast Asia: A Lao study. International Journal of Sexual Health, 21(1), 35-48. doi: 10.1080/19317610802554141

Winter, S., Settle, E., Wylie, K., Reisner, S., Cabral, M., Knudson, G., \& Baral, S. (2016). Synergies in health and human rights: A call to action to improve transgender health. The Lancet, 2016(June 17), 13. doi: 10.1016/S0140-6736(16)30653-5

Wolfradt, U., \& Neumann, K. (2001). Depersonalisation, self-esteem and body image in male-to-female transsexuals compared to male and female controls. Archives of Sexual Behaviour, 30(3), 301-310.

Wood, A. W., \& Conley, A. H. (2014). Loss of religious or spiritual identities among the LGBT population. Counselling and Values, 59(1), 95111. doi: 10.1002/j.2161-007X.2014.00044.X

Wu, C.-u. (2012a). Performing transgender desire: Male cross-dressing. In H. Chiang (Ed.), Transgender China (pp. 225-262). New York: Palgrave Macmillan.

$\mathrm{Wu}$, G.-p. 吳. (2011). On transgender's right of gender transition after marriage and the relationship in marriage and family 變性人婚後變 性權及其婚姻家庭關係問題探析. Journal of Southwest University of Political Science and Law 西南政法大學學報, 13(3), 59-68. doi: 10.3969/j.issn.1008-4355.2011.03.08

$\mathrm{Wu}, \mathrm{G}$.-p. 吳. (2012b). On the right of natural person's gender transition after marriage 已婚者變性權問題初探. Journal of Poltical Science and Law 政法學刊, 29(3), 5-10.

Xiong, Y. D. 熊. (2014). Social media and gender identity of transgender people: An example of a transgender group on facebook 網路社區 
與跨性別者的身份認同：以Facebook某跨性別者小組為例.

Journalism and Communication 新聞傳播, 9, 120-121.

Yadegarfard, M., Ho, R., \& Bahramabadian, F. (2013). Influences on loneliness, depression, sexual-risk behaviour and suicidal ideation among Thai transgender youth. Culture, Health and Sexuality, 15(6), 726-737. doi: 10.1080/13691058.2013.784362

Yin, R. K. (1989). Case study research: Design and methods. Newbury Park, California: SAGE Publications, Inc.

Yin, R. K. (2003). Applications of case study research (2nd ed.). Thousand Oaks, California: SAGE Publications, Inc.

Yin, R. K. (2009). Case study research: Design and methods (4th ed.). Thousand Oaks, California: SAGE Publications, Inc.

Youngson, R. M. (1999). The madness of Prince Hamlet and other extraordinary states of mind. London: Robinson Publishing Limited. Zhang, Q. F. (2015). Sexuality and the official construction of occidentalism in Maoist and early post-Mao China. European Journal of Cultural Studies, 18(1), 86-107. doi: 10.1177/1367549414557807

Zhou, Z. (2012). The androgynous ideal in scholar-beauty romances: A historical and cultural view. In H. Chiang (Ed.), Transgender China (pp. 97-126). New York: Palgrave Macmillan.

Fung Kei Cheng independent researcher. Hong kong

E-mail address: oasischeng@yahoo.com 